\title{
Hemorrhagic bullae in henoch-schonlein purpura: A case report
}

\author{
S. Parajuli ${ }^{1}$, U. Paudel ${ }^{2}$, D. P. Koirala ${ }^{3}$,A. R. Ojha ${ }^{3}$ \\ ${ }^{1}$ Department of Dermatolgoy, College of Medical Sciences, Bharatpur, Nepal, ${ }^{2}$ Department of Dermatology, Venereology, and \\ Leprology Chitwan Medical College, Bharatpur, Nepal, ${ }^{3}$ Department of childhealth, Institute of Medicine, Maharajgung, \\ Katmandu, Nepal
}

\begin{abstract}
We report a case of ten year old male child of Henoch-Schönlein purpura (HSP) who presented initially with predominant hemorrhagic bullae in extremities. Initial presentation with bullae is rare in HSP. The child recovered within two weeks with a course of systemic and topical steroid without any sequel.
\end{abstract}

Key words: Bullae, extremities, steroid.

\section{Introduction}

Henoch- Schönlein purpura consists of a tetrad of palpable purpura, arthritis, gastrointestinal involvement and renal glomerular involvement. ${ }^{1}$ Annual incidence of HSP has been estimated to be 12.9 per 100,000 children under the age of 17 years across the globe. ${ }^{2}$ Males are affected twice as frequently as females. A patient is said to have HSP if at least two of the following four criteria's are present. 1. Palpable purpura not related to thrombocytopenia 2.Age 20 yrs or younger at onset 3.Bowel angina 4.Histology changes showing granulocytes in the walls of arterioles or venules. ${ }^{3}$ Bullae are rarely seen in HSP. Here we report a case of HSP with bullae because of its rare presentation.

\section{Case history}

A ten years old male child presented with bullae in both lower extremities of seven days duration (fig1). It initially started as petechiae which later changed into

Correspondence: S. Parajuli

E-mail: sudipparajuli@gmail.com painful bullae and spread to buttocks and had also involved outer aspect of upper limb in last two days (fig 2). The lesions had spared mucous membrane, palms and soles. There was no history of joint or abdominal pain. However, he had abdominal pain during the course of treatment in hospital. There was no any history of fever, sore throat, abnormal movements of limbs or bleeding from any other sites. There was no similar history in past. He denied any other drug intake prior to illness. On examination of skin there were predominantly multiple tender hemorrhagic bullae of varying size with scanty scattered petechiae and purpura in between distributed over extensor aspect of bilateral upper and lower limb. Nikolsky sign was negative. Systemic examination was normal. His full blood count, clotting profile, renal function, urine routine, ANA, ds DNAs were normal except for raised ESR and positive occult blood in stool. The biopsy of the skin lesion showed leucocytoclastic vasculitis. He was treated with oral 
S. Parajuli et al, Hemorrhagic bullae in henoch-schönlein purpura: A case report

prednisolone $(2 \mathrm{mg} / \mathrm{kg} /$ day) along with topical triamcinolone and gentamicin twice daily for two weeks and decompression of bullae was done. Steroid was tapered over next 2 weeks. His lesion gradually subsided over a period of two weeks.

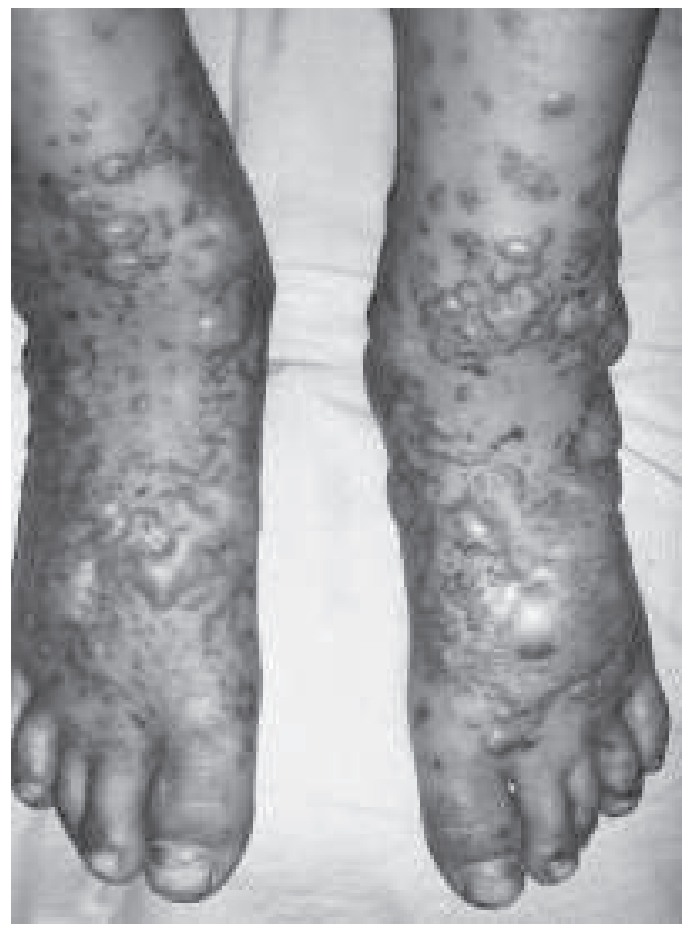

Fig-1

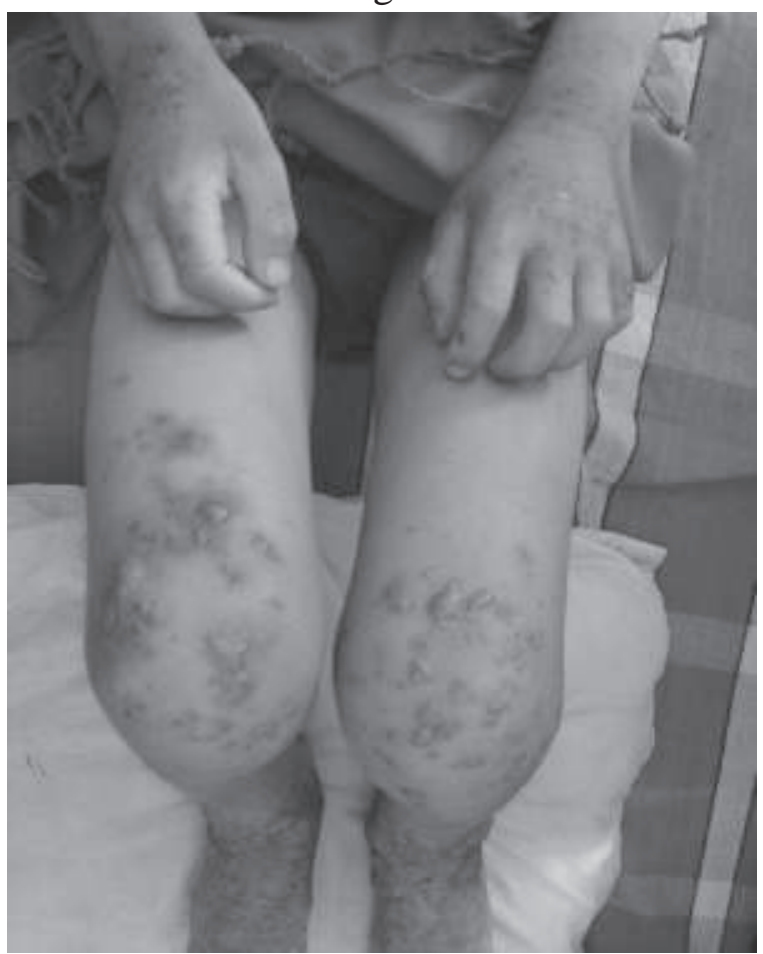

Fig-2

\section{Discussion}

HSP is the most common form of vasculitis in childhood. ${ }^{4}$ The cutaneous findings are typically erythematous urticarial papules, which may evolve within $24 \mathrm{hrs}$ into palpable purpura with hemorrhage. Our patient presented mainly with hemorrhagic bullae. Bullous presentation in childhood is rare. In a study in children less than $2 \%$ had bullous lesion. ${ }^{5}$ In contrast, $60 \%$ of adults with HSP had bullous lesion . ${ }^{6}$

Other cutaneous finding in HSP may include necrotic ulcers. This diversity of cutaneous findings causes confusion in diagnosis, especially when the patient present initially with only vesicle and bullae.

After admission our patient developed gastrointestinal symptoms which were not present initially and his stool for occult blood was positive. However there was neither renal glomerular involvement and nor he had joint pains. In patients with HSP, renal involvement is common, occurring in approximately $30-90 \%$, gastrointestinal bleeding being demonstrated in 50$75 \%$ and arthritis seen in about $75 \%$ of patients. ${ }^{1}$

Biopsy of skin lesion showed leukocytoclastic vasculitis. Direct immunofluorescense showed perivascular IgA deposits. Perivascular IgA deposits are characteristic of HSP and can help to distinguish it from other vasculitides and other bullous disorder. However no laboratory tests are specific for HSP. ${ }^{1}$ HSP is thus a clinical diagnosis to be confirmed with routine histology and direct immunofluorescence.

The patient recovered in 2 weeks with a course of topical and systemic steroid without any complications. The presence of bullae may thus not be a prognostic indicator. 
Journal of College of Medical Sciences-Nepal,2010,Vol-6,No-4

\section{Conclusion}

Most commonly, HSP manifests at the outset with the classic findings of purpura, arthalgia and abdominal pain. Bullae though rare can be a presenting feature in case of HSP without any other initial systemic manifestation.

\section{References}

1. K.L. Barham, J.L. Jorizzo, B. Grattan et al Vasculitis and Neutrophilic Vascular reactions Textbook of Dermatology by; T Burns Vol.3; Seventh edition, Blackwell Publishing 2004;49.1-49.

2. Y.H. Yang, C.F. Hung, C.R. Hsu, et al. A nationwide survey of epidemiological characteristics of childhood
Henoch- Schonlein purpura in Taiwan. Rheumatology $2005 ; 44: 618-22$.

3. J.A. Mills, B.A. Michel, D.A. Bloch. et al. The American college of Rheumatology 1990 criteria for the classification of Henoch Schonlein purpura. Arthritis Rheum 1990; 33:1114-21

4. F.T. Saulsbury Henoch- Schönlein purpura in children. Report of 100 patients and review of the literature. Medicine 1999; 78:395-409.

5. A.Y.K. Abdel, Z. Hejai, H.A. Majeed Henoch- Schönlein purpura in Arab children. Analysis of 52 cases. Trop Geogr Med 1990; 42:52- 7.

6. E.B Tancrede, S. Ochonisky, M.D.V. Parmanen et al Schönlein- Henoch purpura in adult patient. Predictive factors for IgA glomerulonephritis in a retrospective study of 57 cases. Arch Dermatol 1997; 133:438-42. 